\title{
TITLE:
}

\section{Infinite-layer iron oxide with a square-planar coordination}

\section{$\operatorname{AUTHOR}(\mathrm{S}):$}

Tsujimoto, Yoshihiro; Tassel, Cedric; Hayashi, Naoaki; Watanabe, Takashi; Kageyama, Hiroshi; Yoshimura, Kazuyoshi; Takano, Mikio; Ceretti, Monica; Ritter, Clemens; Paulus, Werner

\section{CITATION:}

Tsujimoto, Yoshihiro ...[et al]. Infinite-layer iron oxide with a squareplanar coordination. Nature 2007, 450: 1062-1065

\section{ISSUE DATE:}

2007-12

URL:

http://hdl.handle.net/2433/85019

\section{RIGHT:}

c 2007 Nature Publishing Group.; この論文は出版社版でありません。 引用の際には出版社版をご確認ご利用ください。; This is not the published version. Please cite only the published version. 


\section{Infinite layer iron oxide with a square-planar coordination by low temperature synthesis}

Y. Tsujimoto $^{1}$, C. Tassel ${ }^{1,2}$, N. Hayashi ${ }^{3}$, T. Watanabe ${ }^{1}$, H. Kageyama ${ }^{1}$, K. Yoshimura ${ }^{1}$,

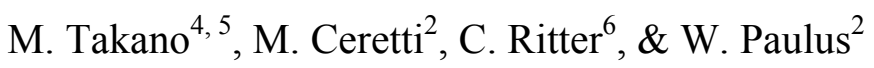

${ }^{1}$ Department of Chemistry, Graduate School of Science, Kyoto University, Sakyo, Kyoto 606-8502, Japan.

${ }^{2}$ University of Rennes 1, Sciences Chimiques de Rennes UMR CNRS 6226, Campus de Beaulieu Bât 10B, Rennes cedex 35042, France.

${ }^{3}$ Graduate School of Human and Environmental Studies, Kyoto University, Sakyo, Kyoto 606-8501, Japan.

${ }^{4}$ Institute for Chemical Research, Kyoto University, Uji, Kyoto 611-0011, Japan.

${ }^{5}$ Research Institute for Production Development, 15 Morimoto, Shimogamo, Sakyo, Kyoto 606-0805, Japan.

${ }^{6}$ Institute Laue Langevin, B. P. 156, 38042, Grenoble, France. 
Conventional high-temperature reaction limits the control of coordination polyhedra in transition-metal oxides to only those obtainable within the bounds of known coordination geometries for a given transition metal ${ }^{1}$. For example, iron atoms are almost exclusively coordinated by 3D polyhedra such as tetrahedra and octahedra. However, recent works have shown that binary metal hydrides act as reducing agents at low temperatures, allowing access to unprecedented structures ${ }^{2-}$ 4. Here we show for the first time the reaction of a perovskite $\mathrm{SrFeO}_{3}$ with $\mathrm{CaH}_{2}$ to yield $\mathrm{SrFeO}_{2}$, a new compound bearing a square-planar oxygen coordination around $\mathrm{Fe}^{2+} \cdot \mathrm{SrFeO}_{2}$ is isostructural with "infinite layer" cupric oxides ${ }^{5-8}$, and exhibits a magnetic order far above room temperature in spite of the 2D structure, indicating fairly strong in-layer magnetic interactions due to extremely strong FedOp hybridization. The $\mathrm{Fe}^{2+}$ ion with $D_{4 h}$ point symmetry remains free from instability due to twofold orbital-degeneracy in the ground state down to low temperatures. From chemical aspect, the impact is that the reduction and the oxidation between $\mathrm{SrFeO}_{2}$ and $\mathrm{SrFeO}_{3}$, both proceeding via the brownmilleritetype intermediate $\mathrm{SrFeO}_{2.5}$, starts at such low-temperatures of $\sim 400 \mathrm{~K}$, which sheds light on how to lower the working temperatures of catalysis, oxygen ion conductors, oxygen gas absorbers, and others.

The coordination number in ionically bonded structures is governed by the relative size of oppositely charged ions, which to a first approximation may be regarded as charged rigid spheres (Pauling's first rule) ${ }^{1}$. Each ion tries to surround itself symmetrically with the largest possible number of oppositely charged neighbors. Transition metal ions normally have, owing to their relatively small ionic radii, a preference for tetrahedral and octahedral coordination, as found typically in perovskites and spinels. 
Pronounced effect on the stereochemistry, or a substantial deviation from ideal geometry, is observed for the Jahn-Teller ions with $\left(e_{\mathrm{g}}\right)^{1}$ or $\left(e_{g}\right)^{3}$ configuration, such as $\mathrm{Cr}^{2+}, \mathrm{Mn}^{3+}\left(d^{4}\right)$ and $\mathrm{Cu}^{2+}, \mathrm{Ni}^{+}\left(d^{9}\right)$ for an octahedral coordination, where the lengthening of a pair of bonds perpendicular to the equatorial plane gives a tetragonal distortion $(c / a>1)$ and results ultimately in a square-planar coordination ${ }^{1}$. Among many oxocuprates with square planar geometry, the series $A \mathrm{CuO}_{2}(A=\mathrm{Sr}, \mathrm{Ca})^{5,6}$ are known as the "infinite-layer compounds", or the mother structure of high- $T_{\mathrm{c}}$ superconductors ${ }^{7,8}$, which consist of a sequence of infinitely repeating stacking of squared $\mathrm{CuO}_{2}$ square lattices. The isostructural phase of $\mathrm{LaNiO}_{2}$ is naturally formed since monovalent nickel is isoelectronic with divalent copper ${ }^{9}$. Unusual coordination beyond the constraint of the ionic model may occur in association with covalent bonding, which is highly directional, realized, as realized, for example, in many silicates and sulfides ${ }^{10}$. A successful approach for exploring unusual coordinations in molecular compounds is the use of organic ligands with specific sterical constraints ${ }^{11,12}$. This cannot be applied, however, to nonmolecular inorganic solids.

Iron, one of the richest elements in the earth, forms an uncountable number of oxides some of which have been widely used in industry as low cost ferrite magnets and pigments. In almost all of them, the iron ions are tetrahedrally or octahedrally coordinated. To our best knowledge, the only example of square-planar coordination is represented by the mineral, gillespite $\mathrm{BaFeSi}_{4} \mathrm{O}_{10}{ }^{13}$. However, the iron atoms in this oxide are dispersed separately within the building blocks made of four-membered rings of $\mathrm{SiO}_{4}{ }^{4-}$ tetrahedra, rendering the electromagnetic properties of minor interest. Ordered perovskites $\mathrm{CaFe}_{3} \mathrm{Ti}_{4} \mathrm{O}_{12}$ and $\mathrm{CaFeTi}_{2} \mathrm{O}_{6}$ have also been discussed as synthetic examples of the square planar geometry ${ }^{14}$, but they actually have 4 short $(\sim 2.0 \AA)$ and 4 long $(\sim 2.8$ A) Fe-O bonds, resulting in a 3D environment. 
Herein we show a low-temperature route of the topotactic synthesis of a new “infinite-layer" iron oxide, $\mathrm{SrFeO}_{2}$ (Fig. 1b), using an easy-to-prepare, slightly oxygen deficient perovskite $\mathrm{SrFeO}_{3-y}(y \sim 0.125)$ as a precursor (Fig. 1a). The formation of the strongly anisotropic framework of $\mathrm{SrFeO}_{2}$ is remarkable in the senses that (i) the JahnTeller effect should not be of essential importance for divalent iron ions, (ii) such an unusual geometry is obtained for a simple ionic compound and (iii) unlike $\mathrm{BaFeSi}_{4} \mathrm{O}_{10}$, the $\mathrm{FeO}_{2}$ layers form the primary building blocks, making it a quasi-2D magnet. Furthermore, the oxygen content in $A \mathrm{FeO}_{3-y}(A=\mathrm{Sr}, \mathrm{Ca})$ has been taken for granted to be in the range of only $0 \leq y \leq 0.5$, and thus the brownmillerite phase $\mathrm{SrFeO}_{2.5}(y=0.5)$ (please see Supplementary Information Figure 1), consisting of alternative $\mathrm{FeO}_{6}$ octahedra- and $\mathrm{FeO}_{4}$ tehrahedra-layers, was historically assumed to represent the lower limit of oxygen stoichiometry. This is in spite of extensive experimental efforts to control oxygen content that include synthesis at high temperature with oxygen partial pressures ranging from $10^{-9}$ to $100 \mathrm{MPa}^{15,16}$, electrochemical reaction in aqueous solution at room temperature $^{17}$, and the fabrication of epitaxial films under different atmosphere ${ }^{18}$.

The present approach follows the recent success in the use of hydrides of electropositive metals as powerful reducing agents ${ }^{2-4}$ 19-22, e.g., $\mathrm{NaH}$ to yield $\mathrm{LaSrCoO}_{3.38}$ from $\mathrm{LaSrCoO}_{4}{ }^{2}, \mathrm{YSr}_{2} \mathrm{Mn}_{2} \mathrm{O}_{5.5}$ from $\mathrm{YSr}_{2} \mathrm{Mn}_{2} \mathrm{O}_{7}{ }^{19}$, and $\mathrm{CaH}_{2}$ to yield $\mathrm{LaSrCoO}_{3} \mathrm{H}_{0.7}$ from $\mathrm{LaSrCoO}_{4}{ }^{3}, \quad \mathrm{Yb}_{2} \mathrm{Ti}_{2} \mathrm{O}_{6.43}$ from $\mathrm{Yb}_{2} \mathrm{Ti}_{2} \mathrm{O}_{7}{ }^{4}, \quad \mathrm{La}_{3} \mathrm{Ni}_{2} \mathrm{O}_{6}$ from $\mathrm{La}_{3} \mathrm{Ni}_{2} \mathrm{O}_{7}{ }^{20}$. These metal hydrides, routinely used as drying agents in organic synthesis, are now regarded as promising reducing agents for nonmolecular compounds to yield unusual frameworks and coordinations in nonmolecular solids, since they are active at considerably lower temperature as compared to conventional techniques. They also allow to avoid solution chemistry. However, their potential for the synthesis of new nonmolecular compounds still seems far from being exploited. 
The reduction of $\mathrm{SrFeO}_{2.875}$ was performed using $\mathrm{CaH}_{2}$ as a reducing agent, as described for $\mathrm{LaSrCoO}_{4}{ }^{3}$. $\mathrm{SrFeO}_{2.875}$ and a two-molar excess of $\mathrm{CaH}_{2}$ were finely ground in an Ar-filled glove box, sealed in an evacuated Pyrex tube, and reacted at 553 $\mathrm{K}$ for 2 days. The residual $\mathrm{CaH}_{2}$ and the $\mathrm{CaO}$ byproduct were removed from the final reaction phase by washing them out with a $\mathrm{NH}_{4} \mathrm{Cl} /$ methanol solution. Chemical analyses were based on energy dispersive spectroscopy (EDS) and thermogravimetry (TG). The synchrotron powder x-ray diffraction (XRD) experiment was performed on the large Debye-Scherrer camera installed at SPring- 8 BL02B2 by using an imaging plate as a detector. The wavelength of the x-ray is $0.77747 \AA$. Ex-situ neutron powder diffraction (NPD) studies were carried out on the D1A diffractometer, installed at the Institute Laue Langevin (ILL). The wavelengh of $\lambda=1.91 \AA$ was employed. The in-situ NPD profiles upon warming in dynamic vacuum was carried out on the D1B diffractometer installed at ILL, where $\lambda=2.52 \AA$ was used. ${ }^{57} \mathrm{Fe}$ Mössbauer spectra were taken under dynamical vacuum using a ${ }^{57} \mathrm{Co} / \mathrm{Rh}$ source and a control absorber of $\alpha$-Fe.

The powder XRD patterns of the precursor phase $\mathrm{SrFeO}_{2.875}$ (i.e., $\mathrm{Sr}_{8} \mathrm{Fe}_{8} \mathrm{O}_{23}$ ) were assigned as the nearly cubic perovskite phase with $a_{\mathrm{p}} \sim 3.86 \AA$, though it in fact had a tetragonal $2 a_{\mathrm{p}} \sqrt{2} \times 2 a_{\mathrm{p}} \sqrt{ } 2 \times 2 a_{\mathrm{p}}$ supercell (I4/mmm, $a=10.929 \AA$ and $\left.c=7.698 \AA\right)$, consistently with the leteratures ${ }^{15,16}$. On the other hand, the synchrotron XRD patterns of the final product (please see Supplementary Information Figure 2) were readily indexed assuming the tetragonal unit cell with $a=3.99107(3) \AA$ and $c=3.47481(5) \AA$, which is completely different from those of any reported $\mathrm{SrFeO}_{3-y}(0 \leq y \leq 0.5)$ phases. No extra diffraction lines were detected. As compared with the lattice parameters $\left(a_{\mathrm{p}} \sim 3.86\right.$ $\AA$ ) of the precursor, the $a$ axis of the final product is slightly increased, while the $c$ axis is drastically decreased. This implies an anisotropic extraction of oxygen atoms located originally on the $c$ axis. Furthermore, the similarity of the lattice parameters to those of $\mathrm{SrCuO}_{2}(a=3.926 \AA \text { and } c=3.432 \AA)^{6}$ and also the fact that no specific extinction rules 
for reflections could be determined from the diffraction pattern, strongly suggest that the two phases are isostructural in the space group of $P 4 / \mathrm{mmm}$. The Rietveld refinement from the synchrotron data immediately converged to $R_{\mathrm{wp}}=6.04 \%$ and $\chi^{2}=4.41$ along with reasonable individual, isotropic displacement factors for all the atoms, suggesting successful structural analysis. The refinement of the site occupancy factor for oxygen atoms gave $0.994(8)$, indicating that the occupation of the oxygen $(2 f)$ position is unity within the standard deviation. Inclusion of oxygen atoms into the apical (1b) site did not improve the refinement. The bond valence sum calculations gave the valences of +1.92 for $\mathrm{Sr}$ and +1.97 for $\mathrm{Fe}$, which are in excellent agreement with the expected valences of +2 for the both. The elemental analysis by EDS before and after the reduction gave the same molar ratio of $\mathrm{Sr}: \mathrm{Fe}=1: 1$.

The NPD patterns of $\mathrm{SrFeO}_{2}$ at $293 \mathrm{~K}$ (Fig. 2a) confirmed the aforementioned structure with an excellent convergence $\left(R_{\mathrm{wp}}=4.70 \%\right.$ and $\left.\chi^{2}=3.18\right)$. They also excluded a possible incorporation of hydrogen into the structure, and revealed the presence of the $(\pi, \pi, \pi)$ antiferromagnetic order, where the magnetic moments are directed perpendicularly to the $c$ axis (Fig. 2b). This is the same spin structure as that of the undoped, antiferromagnetically ordered mother phase of high- $T_{\mathrm{c}}$ cupric oxide superconductors. The magnetic moment has been found to be $3.1 \mu_{\mathrm{B}} / \mathrm{Fe}$ at $293 \mathrm{~K}$ and 3.6 $\mu_{\mathrm{B}} / \mathrm{Fe}$ at $10 \mathrm{~K}$ (please see Supplementary Information Figure 3). The magnitude itself and its minor variation over the wide temperature range strongly suggest that the ferrous ions are in high-spin state of $\left(d_{y z}, d_{z x}\right)^{3}\left(d_{x y}\right)^{1}\left(d_{z 2}\right)^{1}\left(d_{x 2-y 2}\right)^{1}$ with $S=2$ and that the antiferromagnetic transition temperature is considerably higher than room temperature. The magnetic order at ambient temperature was also evidenced by ${ }^{57} \mathrm{Fe}$ Mössbauer spectroscopy at $285 \mathrm{~K}$ (Fig. 3b) showing six well-defined peaks with a fairly large hyperfine field of $40.1 \mathrm{~T}$. 
The temperature variations of the magnetic NPD peak intensity and the hyperfine field nicely coincide with each other (see Figs. 3a and 3c, and Supplementary Information Table 1), giving $T_{\mathrm{N}}=473 \mathrm{~K}$. The quadrupole interaction appearing in the magnetically split Mössbauer spectrum, which is equal to $S_{1}-S_{2}$ in Fig. 3 b, is almost temperature-independent around the room temperature value of $1.16 \mathrm{~mm} / \mathrm{s}$, and this value is very close to the quadrupole splitting in the paramagnetic state, $\Delta E$ (the same figure), of $1.06 \mathrm{~mm} / \mathrm{s}$. This proximity and the fact that the electric field gradient is uniaxial along the $c$ axis by symmetry indicated that the magnetic hyperfine field lies in the $a b$ plane $\mathrm{e}^{23}$, in consistency with the NPD results.

In spite of the apparent two dimensionality in magnetism, the $T_{\mathrm{N}}$ is considerably higher than that $(\sim 200 \mathrm{~K})$ of $\mathrm{FeO}$ having the rock salt type, three-dimensionally extended linear Fe-O-Fe bonding. This demonstrates that $\mathrm{SrFeO}_{2}$ has fairly large inplane exchange constants due to strong in-plane $\mathrm{Fe} d_{x 2-y 2}-\mathrm{O} p_{x, y}$ hybridization. Another aspect of the strong hybridization is the isomer shift $(\sim 0.5 \mathrm{~mm} / \mathrm{s}$ at room temperature) which is located in the extreme covalent limit for a high-spin divalent iron ${ }^{23}$. It is also interesting to point out that the electronic configuration should be a two-fold orbital degenerate ground state of $\left(d_{x z}, d_{y z}\right)^{1}$, since all iron atoms in $\mathrm{SrFeO}_{2}$ are in a high-spin state with $D_{4 \mathrm{~h}}$ point symmetry. Remarkably enough, $\mathrm{SrFeO}_{2}$ is free from instabilities such as orbital ordering or Jahn-Teller distortion even at $10 \mathrm{~K}$ and $4.2 \mathrm{~K}$ as concluded from NPD and Mössbauer spectroscopy, respectively. We believe that the orbital instability is overcome by the extremely strong covalency that favors directional and symmetrical Fe-O bonding. Therefore, by applying the present synthetic approach to other iron oxides like conventional ferrites, one would be able to obtain novel magnetic materials containing $\mathrm{Fe}^{2+}$ ions in square-planer geometry and thus with greater magnetic anisotropy and higher transition temperatures. 
$\mathrm{SrFeO}_{3-y}$ and related iron perovskite oxides have been intensely studied since they exhibit fast oxygen transport combined with high electron conductivity already at low temperatures ${ }^{17}$. They are thus potential candidates for applications as electrodes for solid oxide fuel cells (SOFCs) and batteries ${ }^{24}$, membranes for oxygen separation ${ }^{25}$ and electrocatalysis ${ }^{26}$ and gas sensors ${ }^{27}$. In addition, they have attracted academic interests concerning vacancy orderings (at $y=0,0.125,0.25$ and 0.5$)^{15-17}$, charge disproportionation $^{28}$, giant magnetoresistance ${ }^{29}$, helical antiferromagnetic spin structure $^{30}$, and high-spin to low-spin transition ${ }^{28}$. The present study concerns the former aspect by demonstrating that the reduction of $\mathrm{SrFeO}_{2.875}$ does not necessarily stop at the brownmillerite structure $\mathrm{SrFeO}_{2.5}$, but goes beyond this stoichiometry to form a terminal phase with infinite $\left(\mathrm{FeO}_{2}\right)_{\infty}$ layers. It means that $\mathrm{CaH}_{2}$ can provide a balanced reducing potential that is high enough to produce $\mathrm{SrFeO}_{2}$ but not too high to result in over-reduction to $\mathrm{Fe}$ metal. Starting from $\mathrm{SrFeO}_{3-y}$, a 1-day reaction at 473 $\mathrm{K}<T<523 \mathrm{~K}, 523 \mathrm{~K}<T<673 \mathrm{~K}, 673 \mathrm{~K}<T$, produces $\mathrm{SrFeO}_{2.5}, \mathrm{SrFeO}_{2}$ and $\mathrm{SeO}-\mathrm{Fe}$ mixture, respectively, while a 1 -week reaction at $473 \mathrm{~K}$ yields only $\mathrm{SrFeO}_{2}$, demonstrating ever more feasible control of reducing power by varying synthetic temperature and time.

It is interesting to note that the reduction from $\mathrm{SrFeO}_{2.5}$ to $\mathrm{SrFeO}_{2}$ is not a naïve topotactic reduction because it involves the filling of the originally vacant sites within the tetrahedral layers of $\mathrm{SrFeO}_{2.5}$. Upon heating in an oxygen atmosphere of $0.1 \mathrm{MPa}$, an opposite reaction back up to $\mathrm{SrFeO}_{2.875}$ via $\mathrm{SrFeO}_{2.5}$ takes place (please see Supplementary Information Figure 4). Surprisingly, both the reduction and the oxygen uptake proceeds already at temperatures as low as $\sim 400 \mathrm{~K}$. This implies not only that oxygen is highly mobile in solids at low temperatures, but also that a given dense framework can rearrange towards new oxygen-ordered structures. This fact may impact on the studies of SOFCs, oxygen membranes and sensor materials oriented toward 
reduction of working temperatures. Concerning the interest in electronic properties, investigation of hole- or electron-doping into the $\left(\mathrm{FeO}_{2}\right)_{\infty}$ sheets e.g. by introducing selectively apical oxygen atoms or by replacing $\mathrm{Sr}$ sites with a monovalent metal like $\mathrm{Na}$ would be interesting.

\section{References}

1. Wells, A. F. Structural inorganic chemistry 3rd edn. OxfordUniversity Press, 1962.

2. Hayward, M. A. \& Rosseinsky, M. J. Anion vacancy distribution and magnetism in the new reduced layered $\mathrm{Co}(\mathrm{II}) / \mathrm{Co}(\mathrm{I})$ phase $\mathrm{LaSrCoO}_{3.5-x}$, Chem. Mater.12, 2182-2195 (2000).

3. Hayward, M. A., Cussen, E. J., Claridge, J. B., Bieringer, M., Rosseinsky, M. J. et al. The hydride anion in an extended transition metal oxide array: $\mathrm{LaSrCoO}_{3} \mathrm{H}_{0.7}$. Science 295, 1882-1884 (2002).

4. Blundred, G. D., Bridges, A. B. \& Rosseinsky, M. J. New Oxidation States and Defect Chemistry in the Pyrochlore Structure, Angew. Chem. Int. Ed. 43, 3562-3565 (2004).

5. Siegrist, T., Zahurak, S. M., Murphy, D. W. \& Roth, R. S. The parent structure of the layered high-temperature superconductors, Nature 334, 231-232 (1988).

6. Takano, M., Takeda, Y., Okada, H., Miyamoto, M. \& Kusaka, T. ACuO $($ A: alkaline earth) crystallizing in a layered structure. Physica C 159, 375-378 (1989).

7. Smith, M. G., Manthiram, M., Zhou, J. \& Goodenough, J. B. Electron-doped superconductivity at $40 \mathrm{~K}$ in the infinite-layer compound $\mathrm{Sr}_{1-y} \mathrm{Nd}_{y} \mathrm{CuO}_{2}$. Nature 351, 549-551 (1991). 
8. Azuma, M., Hiroi, Z., Takano, M., Bando, Y. \& Takeda, Y. Superconductivity at 110 $\mathrm{K}$ in the infinite-layer compound $\left(\mathrm{Sr}_{1-x} \mathrm{Ca}_{x}\right)_{1-y} \mathrm{CuO}_{2}$. Nature 356, 775-776 (2002).

9. Crespin, M., Levitz, P. \& Gatineau, L. Reduced forms of $\mathrm{LaNiO}_{3}$ perovskite. 1 . Evidence for new phases: $\mathrm{La}_{2} \mathrm{Ni}_{2} \mathrm{O}_{5}$ and $\mathrm{LaNiO}_{2}$. J. Chem. Soc., Faraday Trans. 2, 1181-1194 (1983).

10. Hyde, B. G. \& Andersson, S. Inorganic crystal structure, Ch. 15, John Wiley \& Sons, 1989.

11. Berry, J. F., Bill, E., Bother, E., George, S. D., Mienert, B. et al. An octahedral coordination complex of iron(VI). Science 312, 1937-1941 (2006).

12. Bouwkamp, M. W., Bowman, A. C., Lobkovsky, E. \& Chirik. P. J. Iron-Catalyzed $[2 \pi+2 \pi]$ Cycloaddition of $\alpha, \omega$-Dienes: The Importance of Redox-Active Supporting Ligands, J. Am. Chem. Soc. 128, 13340-13341 (2006).

13. Hazen, R. M. \& Burnham, C. W. The crystal structures of gillespite I and II: a structural determination at high pressure. Am. Mineral. 59, 1166-1176 (1974).

14. Leinenweber, K., Linton, J., Navrotsky, A., Fei, Y. \& Parise, J. B. High-pressure perovskites on the Join $\mathrm{CaTiO}_{3}-\mathrm{FeTiO}_{3}$. Phys. Chem. Minerals 22, 251-258 (1995).

15. Takeda, Y., Kanno, K., Takada, T., Yamamoto, O., Takano, M. et al. Phase relation in the oxygen nonstoichiometric system $\operatorname{SrFeO}_{x}(2.5 \leq x \leq 3)$. J. Solid State Chem. 63, 237-249 (1986).

16. Hodges, J. P., Short. S., Jorgensen, J. D., Xiong, X., Dabrowski, B. et al. Evolution of oxygen-vacancy ordered crystal structures in the perovskite series $\operatorname{Sr}_{n} \mathrm{Fe}_{n} \mathrm{O}_{3 n-1}(n=2$, 4,8 , and $\infty$ ), and the relationship to electronic and magnetic properties. J. Solid State Chem. 151, 190-209 (2000). 
17. Grenier, J-C., Wattiaux, A., Doumerc, J-P., Dordor, P., Fournes, L. et al. Electrochemical oxygen intercalation into oxide networks. J. Solid State Chem. 96, 2030 (1992).

18. Hayashi, N., Terashima, T., \& Takano, M. Oxygen-holes creating different electronic phases in $\mathrm{Fe}^{4+}$-oxides: Successful growth of single crystalline films of $\mathrm{SrFeO}_{3}$ and related perovskites at low oxygen pressure. J. Mat. Chem. 11, 2235 (2001).

19. Hayward, M. A. Structural and magnetic properties of topotactically reduced $\mathrm{YSr}_{2} \mathrm{Mn}_{2} \mathrm{O}_{7-x}(0<x<1.5)$. Chem. Mater. 18, 321-327 (2006).

20. Poltavets, V. V., Lokshin, K. A., Dikmen, S., Croft, M., Egami, T. et al. $\mathrm{La}_{3} \mathrm{Ni}_{2} \mathrm{O}_{6}$ : a new double $\mathrm{T}^{\prime}$-type nickelte with infinite $\mathrm{Ni}^{1+/ 2+} \mathrm{O}_{2}$ layers. J. Am. Chem. Soc. 128, 90509051 (2006).

21. Hayward, M. A. Phase Separation during the Topotactic Reduction of the Pyrocholore $\mathrm{Y}_{2} \mathrm{Ti}_{2} \mathrm{O}_{7}$, Chem. Mater. 17, 670-675 (2005).

22. Hayward, M. A., Green, M. A., Rosseinsky, M. J. \& Sloan, J. Sodium hydride as a powerful reducing agent for topotactic oxide deintercalation: synthesis and characterization of the nickel(I) $\mathrm{LaNiO}_{2}$. J. Am. Chem. Soc. 121, 8843-8854 (1999).

23. Greenwood, N. N. \& Gibb, T. C. Mössbauer Spectroscopy, Chapman and Hall (London) 1971.

24. Shao, Z. \& Haile, S. M. A high-performance cathode for the next generation of solid-state fuel cells. Nature 431, 170-173 (2004).

25. Sammells, A. F., Schwartz, M., Mackay, R. A., Barton, T. F. \& Peterson, D. R. Catalytic membrane reactors for spontaneous synthesis gas production. Catal. Today $\mathbf{5 6}$, 325-328 (2000). 
26. Badwal, S. P. S. \& Ciacchi, F. T. Ceramic membrane technologies for oxygen separation. Adv. Mater. 13, 993-996 (2001).

27. Wang, Y., Chen, J. \& Wu, X. Preparation and gas-sensing properties of perovskitetype $\mathrm{SrFeO}_{3}$ oxide. Mater. Lett. 49, 361-364 (2001).

28. Takano, M., Nasu, S., Abe, T., Yamamoto, K., Endo, S. et al. Pressure-induced high-spin to low-spin transition in $\mathrm{CaFeO}_{3}$. Phys. Rev. Lett. 67, 3267-3270 (1991).

29. Battle, P. D., Green, M. A., Lago, J., Mihut, A., Rosseinsky, M. J., Spring, L. E., Singleton, J. \& Vente, J. F. Magnetoresistance in high oxidation state iron oxides, Chem. Commun., 767, 987-988 (1998).

30. Mostovoy M. Helicoidal ordering in iron perovskite, Phys. Rev. Lett. 94, 137205 (2005).

Supplementary Information is linked to the online version of the paper at www.nature.com/nature.

Acknowledgements We thank Y. Kiuchi, H. Ueda, M. Isobe, Y. Ueda for their help in EDS and TG measurements and K. Kato for his help in the synchrotron $\mathrm{x}$-ray experiments at Spring-8. This work was supported by Young Scientists A (H.K.), the Grant-in-Aid for Scientific Research on Priority Areas (H.K. and K.Y.), Scientific Research S (M.T.) from MEXT. Please see Supplementary Notes for more details.

Author Contributions H.K. designed the study in collaboration with W.P, receiving the aid of M.T.; C.T. performed the initial synthesis and proposed the structural model; Y.T. and T.W. optimized the synthetic conditions, performed chemical characterizations, x-ray diffraction measurements and corresponding structural 
refinement; N.H. conducted the Mössbauer experiment, receiving the aid of M.T.; M.C., C.R. and W.P. performed the neutron diffraction measurements and M.C. and W.P. corresponding structural refinement; All the authors have discussed the results presented; H.K. wrote the manuscript with comments mainly from M.T. and W.P.

Author Information Atomic coordinates and structure factors for the crystal structure of $\mathrm{SrFeO}_{2}$ have been deposited with the ICSD database under accession codes 418603, 418605, 418606. The authors declare no competing financial interests. Correspondence and requests for materials should be addressed to H.K. (kage@kuchem.kyoto-u.ac.jp).

\section{Figure Legends}

Figure 1 Structural transformation via a topotactic route. a, The cubic perovskite $\mathrm{SrFeO}_{3}, \mathbf{b}$, The infinite layer compound $\mathrm{SrFeO}_{2}$. Iron, strontium and oxygen atoms are represented as yellow, blue and red spheres, respectively. For the sake of simplicity, an idealized and stoichiometric cubic phase, obtainable under high oxygen pressure, is demonstrated in a, instead of a distorted, slightly oxygen-deficient phase $\mathrm{SrFeO}_{3-y}$ $(y \sim 0.125)$ used in this study. The oxygen coordination around the iron ions are illustrated by octahedra in $\mathbf{a}$ and squares in $\mathbf{b}$.

Figure 2 Structural characterization of $\mathrm{SrFeO}_{2}$ by Rietveld refinement of highresolution neutron diffraction at room temperature. a, The solid lines and overlying crosses indicate the calculated and observed intensities. The difference between the observed and calculated profiles is plotted at the bottom. $\mathrm{SrFeO}_{2}$ adopts the $P 4 / \mathrm{mmm}$ 
space group, $a=3.991(1) \AA, c=3.474(1) \AA$, Sr on $1 d(0.5,0.5,0.5)$, Fe on $1 a(0,0,0)$ and $\mathrm{O}$ on $2 f(0.5,0,0)$, with $100 \%$ occupancy, $B_{\text {iso }}(\mathrm{Sr})=0.47(5) \AA^{2}, B_{\text {iso }}(\mathrm{Fe})=0.47(4) \AA^{2}$, $B_{\text {iso }}(\mathrm{O})=0.79(5), R_{\mathrm{p}}=3.82 \%, R_{\mathrm{wp}}=4.70 \%, \chi^{2}=3.18, R_{\mathrm{Bragg}}=4.19 \%, R_{\mathrm{mag}}=9.19 \%$. b, the magnetic structure with a $2 a_{\mathrm{p}} \times 2 a_{\mathrm{p}} \times 2 c_{\mathrm{p}}$ magnetic unit cell, where iron sites are drawn. Arrows denote the direction of the magnetic moment.

Figure 3 Temperature evolution of the magnetic order in $\mathrm{SrFeO}_{2}$. a, The in-situ NPD profiles upon warming. The peak at $2 \theta=36^{\circ}$ corresponds to the $(1 / 2,1 / 2,1 / 2)$ magnetic reflection. b, Mössbauer spectra at $290 \mathrm{~K}$ and $473 \mathrm{~K}$. The red lines indicate the spectra from $\mathrm{SrFeO}_{2}$, while the blue line at $473 \mathrm{~K}$ represents the spectrum from a small amount of $\mathrm{SrFeO}_{2.5}$. The black line is the total fit. c, Temperature dependence of the magnetic moment determined by NPD (open) and Mössbauer spectroscopy (solid). The solid curve is the theoretical Brillouin function for $S=2$. Error bars are s.d. determined by the Rietveld refinement.

\section{Methods}

A precursor $\mathrm{SrFeO}_{2.875} \quad(y \sim 0.125)$ was prepared by a conventional hightemperature ceramic method from predried $\mathrm{SrCO}_{3}(4 \mathrm{~N})$ and $\mathrm{Fe}_{2} \mathrm{O}_{3}(4 \mathrm{~N})$. Stoichiometric amounts of $\mathrm{SrCO}_{3}$ and $\mathrm{Fe}_{2} \mathrm{O}_{3}$ were ground together, heated at $1273 \mathrm{~K}$ in air, ground again, and heated for an additional $24 \mathrm{~h}$ at $1273 \mathrm{~K}$. The reduction of $\mathrm{SrFeO}_{2.875}$ was performed using $\mathrm{CaH}_{2}$ as a reducing agent. $\mathrm{SrFeO}_{2.875}(0.45$ grams $)$ and a two-molar excess of $\mathrm{CaH}_{2}$ (0.2 grams) were finely ground in an Ar-filled glove box, sealed in an evacuated Pyrex tube $\left(\mathrm{vol}=15 \mathrm{~cm}^{3}\right)$ with a residual pressure less than $1.3 \times 10^{-8} \mathrm{MPa}$, and 
reacted at $553 \mathrm{~K}$ for 2 days. The residual $\mathrm{CaH}_{2}$ and the $\mathrm{CaO}$ byproduct were removed from the final reaction phase by washing them out with $0.1 \mathrm{M} \mathrm{NH} \mathrm{N}_{4} \mathrm{Cl}$ in dried methanol.

The EDS experiments were carried out for the precursor and the final product using a JOEL (JSM-5600) scanning electron microscope (SEM) equipped with an EDAX (Oxford Link ISIS) microanalytical system. Thermogravimetric (TG) measurements were performed using a Mac Science thermal analyzer (TG-DTA2000). Measurements to analyze reoxidation behavior of $\mathrm{SrFeO}_{2}$ were performed on a sample of around $20 \mathrm{mg}$ that was rapidly loaded into an aluminum crucible and then heated at $10 \mathrm{~K} / \mathrm{min}$ under flowing $\mathrm{O}_{2}(0.1 \mathrm{MPa})$. Prior to the experiment, the sample was dried at $373 \mathrm{~K}$ for about one hour. The identity and oxygen stoichiometry of the reoxidized products were determined by x-ray powder diffraction.

The synchrotron powder diffraction experiment was performed on the large Debye-Scherrer camera installed at SPring-8 BL02B2 by using an imaging plate as a detector. Incident beams from a bending magnet were monochromatized to $0.77747 \AA$. The sample was contained in a glass capillary tube with an inner diameter of $0.1 \mathrm{~mm}$ and was rotated during measurements. The synchrotron x-ray diffraction data were collected at room temperature in a $2 \theta$ range from $1^{\circ}$ to $75^{\circ}$ with a step interval of 0.01 $\circ$.

The ex-situ neutron powder diffraction studies were carried out on the D1A diffractometer, installed at the Institute Laue Langevin (ILL, Grenoble, France). A 200 mg sample sealed in a He filled vanadium can was used and a wavelengh of $\lambda=1.91 \AA$ was employed. The in-situ neutron powder diffraction experiments of $\mathrm{SrFeO}_{2}$ upon warming in dynamic vacuum $\left(P\left(\mathrm{O}_{2}\right)<1.3 \times 10^{-10} \mathrm{MPa}\right)$ were carried out using the ILL vacuum furnace on the D1B diffractometer installed at ILL, where $\lambda=2.52 \AA$ was used. The temperature was varied from $270 \mathrm{~K}$ to $500 \mathrm{~K}$ with a $0.5 \mathrm{~K} / \mathrm{min}$ ramp rate. The 
temperature stability and average temperature were determined using a thermocouple placed at the sample position.

Mössbauer spectra of $\mathrm{SrFeO}_{2}$ were taken under a dynamical vacuum, and the data were collected in transmission geometry by using a ${ }^{57} \mathrm{Co} / \mathrm{Rh} \quad \gamma$-ray source at low temperature in combination with a constant-acceleration spectrometer. The source velocity was calibrated by using pure $\alpha$-Fe as a control material. The low temperature measurements were carried out using a cryostat, while the high temperature spectra were taken with a small amount of $\mathrm{CaH}_{2}$ that was mixed with the $\mathrm{SrFeO}_{2}$ powder to minimize reoxidation of $\mathrm{SrFeO}_{2}$ into the brownmillerite phase $\mathrm{SrFeO}_{2.5}$ upon being heated. The obtained spectra were fitted by Lorentzian function. The subspectrum of $\mathrm{SrFeO}_{2.5}$ observed at high temperatures was compared with that of previously reported $^{31}$.

The x-ray and neutron diffraction patterns were analyzed by the Rietveld method using RIETAN $2000^{32}$ and FULLPROF software ${ }^{33}$, respectively. The agreement indices used were the weighted profile, $R_{\mathrm{wp}}=\left[\sum w_{\mathrm{i}}\left(y_{\mathrm{io}}-y_{\mathrm{ic}}\right)^{2} / \sum w_{\mathrm{i}}\left(y_{\mathrm{io}}\right)^{2}\right]^{1 / 2}$ and the goodness of fit (GOF), $\chi^{2}=\left[R_{\mathrm{wp}} / R_{\mathrm{exp}}\right]^{2}$, where $R_{\exp }=\left[(N-P) / \sum w_{\mathrm{i}} y_{\mathrm{io}}{ }^{2}\right]^{1 / 2}, y_{\mathrm{io}}$ and $y_{\mathrm{ic}}$ are the observed and calculated intensities, $w_{\mathrm{i}}$ is the weighting factor, $N$ is the total number of $y_{\text {io }}$ data when the background is refined, and $P$ is the number of adjusted parameters. Bond valence sum method was applied to estimate the valence of cations using tabulated parameters ${ }^{34}$.

31. Adler, P., Schwarz, U., Syassen, K., Milner, A. P., Pasternak, M. P. \& Hanfland, M. Structural phase transition in $\mathrm{Sr}_{2} \mathrm{Fe}_{2} \mathrm{O}_{5}$ under high pressure, J. Sol. Stat. Chem. 155, $381-388(2000)$

32. Izumi, F. \& Ikeda, T. Rietveld-analysis program RIETAN-98 and its applications to zeolites, Mater. Sci. Forum 321-324, 198-203 (2000). 
33. Rodríguez-Carvajal, J. Recent advances in magnetic-structure determination by neutron powder diffraction. J. Phys. B 192, 55-69 (1993).

34. Brown, I. D. \& Altermatt, D., Bond-valence parameters obtained from a systematic analysis of the inorganic crystal structure database. Acta Cryst. B 41, 244-247 (1985). 


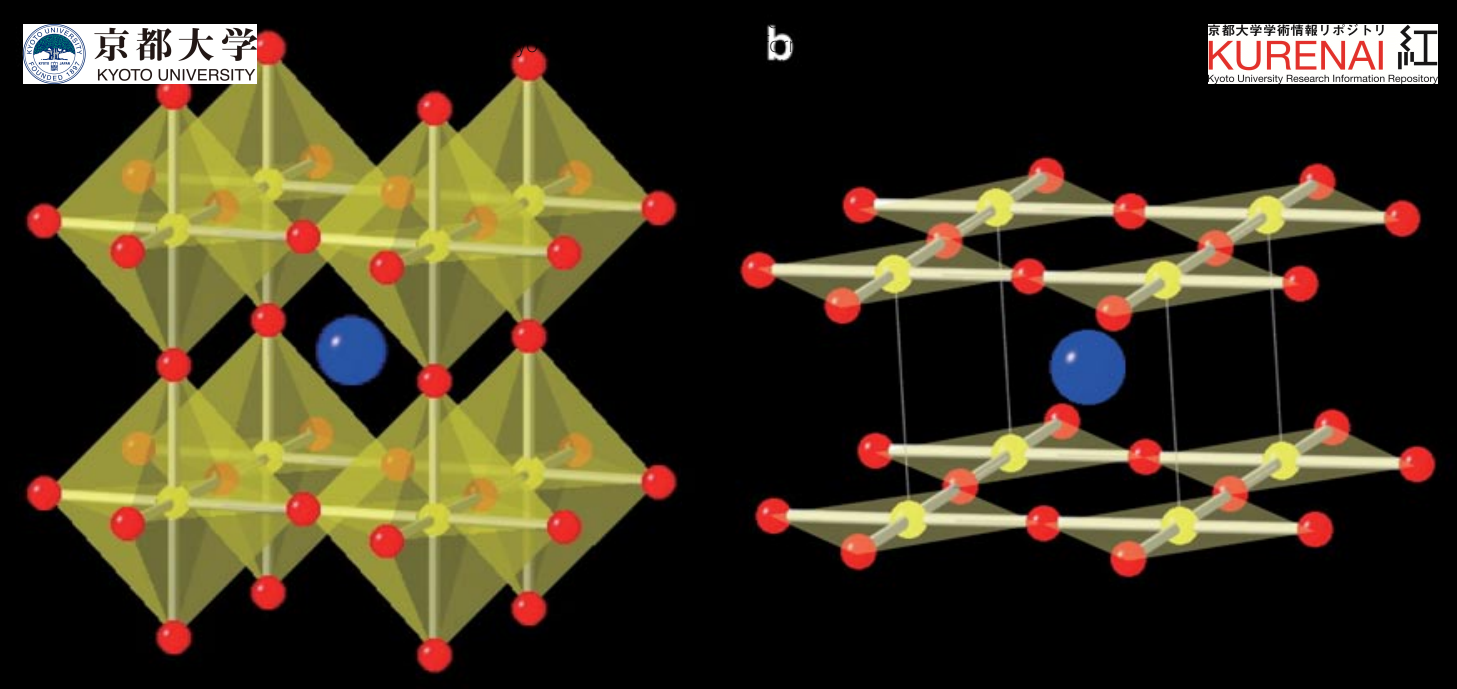



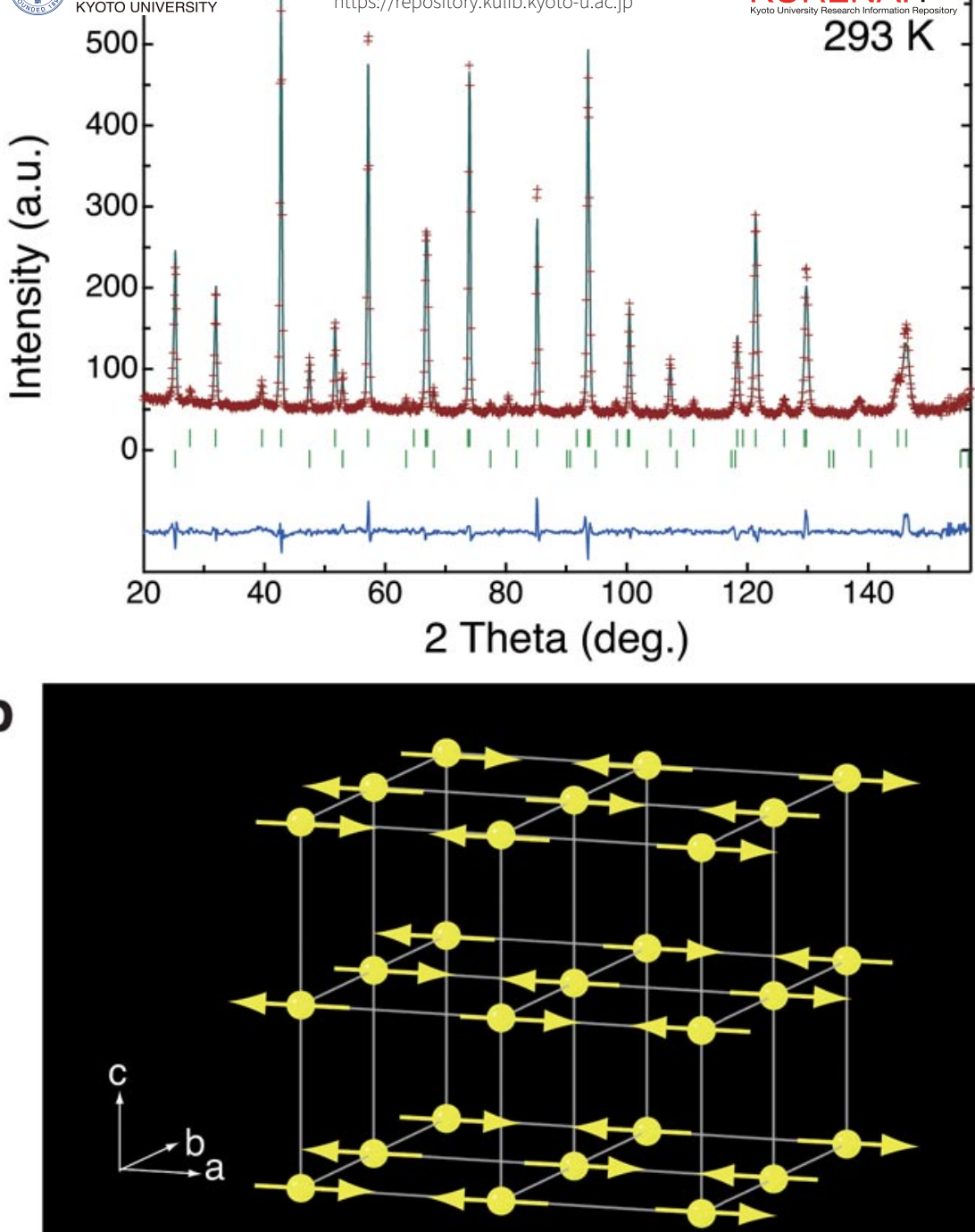
